\title{
GNSS Multipath Error Model for Aircraft Surface Navigation Based on Canonical Scenarios for Class F Airports
}

\author{
Capucine Amielh, ENAC \\ Alexandre Chabory, ENAC \\ Christophe Macabiau, ENAC \\ Laurent Azoulai, Airbus
}

\section{BIOGRAPHIES}

Capucine Amielh graduated as an Electronics and Telecommunication engineer in 2015 from ENAC (Ecole Nationale de l'Aviation Civile) in Toulouse, France. In 2016, she worked as a research engineer in the ElectroMagnetic and Antenna (EMA) and the Signal Processing and Navigation (SIGNAV) reasearch axes of the TELECOM team at ENAC. She is currently a PhD student in the TELECOM team at ENAC. She is working on GNSS multipath model for aircraft surface operations.

\begin{abstract}
Alexandre Chabory graduated in electrical engineering from ENAC, Toulouse, France, in 2001. He obtained the Ph.D. degree in electromagnetics from Paul Sabatier University, Toulouse, in 2004. From 2004 to 2007, he was a Post-Doctoral Scientist with the Eindhoven University of Technology. Since 2007, he has been with the Electromagnetics and Antennas Research Group of the ENAC Telecom lab. He is currently the head of this group. His current research interests include electromagnetic theory and modeling, mainly for aeronautical applications.
\end{abstract}

Christophe Macabiau graduated as an electronics engineer in 1992 from the ENAC (Ecole Nationale de l'Aviation Civile) in Toulouse, France. Since 1994, he has been working on the application of satellite navigation techniques to civil aviation. He received his Ph.D in 1997 and has been in charge of the signal processing lab of ENAC since 2000, where he also started dealing with navigation techniques for urban navigation. He is currently the head of the TELECOM lab of ENAC, that includes research groups on signal processing and navigation, electromagnetics and data communication networks.

Laurent Azoulai graduated as an engineer specialized in automatic systems from the Institut Supérieur de l'Electronique de Paris in 1996. He is currently Senior Expert Navigation Systems within Airbus, with 20 years of experience in Navigation engineering applied to Defence and Aviation Systems.

\begin{abstract}
In this study, the GNSS multipath simulator for aircraft navigation on the airport surface from [1] is used to derive a multipath pseudo-range error model. First the principle of this deterministic-statistical multipath simulator is reminded. A numerical validation of the electromagnetic multipath prediction is made by establishing the channel transfer function and comparing it to the one obtained with an electromagnetic software, FEKO, using the Method of Moments. To illustrate the outputs of such simulator, a comparison to measurements performed at ENAC is given. Then, after reminding the multipath pseudo-range error model that was established in [2], a multipath pseudo-range error model is adapted to ICAO code F airport layouts [3]. This model is based on the identification of canonical scenarios representing the taxi operation phase. The power spectral density of the multipath pseudo-range errors is over-bounded by a first order Gauss-Markov spectral density. An example of application for the taxi on stand taxilane sub-phase is proposed. In this example, the over-bounding distribution fits quite well the power spectral density of the estimated multipath pseudo-range errors.
\end{abstract}

\section{INTRODUCTION}

For surface operations, aircraft ground position and ground velocity can be estimated using a large variety of sensors, such as Global Navigation Satellite System, Inertial Navigation System, Wheel Speed Sensors and others. The sensor bringing global position information with a few meters of error is the GNSS, but measurements from this sensor are affected by signal blockage 
and multipath. The use of GNSS to navigate with guaranteed integrity on the airport surface relies on a valid and efficient GNSS surface multipath error model for airport surface navigation but such kind of multipath error model has not yet been standardized.

In [1], a GPS multipath simulator for airport navigation has been proposed. By means of Geometrical Optics and Physical Optics, this electromagnetic model permits to simulate up to second order interactions between obstacles. The complex airport environment is rendered with uncertainties in the simulated scene such as the building positions and materials. This deterministic approach is therefore enhanced by Monte-Carlo draws on these model parameters as presented in [4]. A multipath ranging error model based on the outputs of the Fortran Multipath Range Error simulator (FMRE) has been proposed in [2]. Over-bouding laws are obtained in [2] to get the mean and the variance of bounding distributions on the pseudo-range errors due to multipath. Moreover, the multipath simulator has been recently enhanced by an antenna+aircraft model specific to ground airport navigation. This electromagnetic model accounts for aircraft structure multipath as well as antenna gain, phase and group delay variations for all direction of arrival in the presence of the close fuselage. Details on this radiating antenna+aircraft model can be found in [5] and [6].

Because of the growth of the number of passengers carried by air transport and the dimensions of new aircraft models, a standardized multipath pseudorange error model seems more and more required to ensure a safe ground navigation and to maintain high airport capacity. To assess the performance of the FMRE multipath pseudorange error model in these conditions, this study is focused on reference code F airports in ICAO classification [3]. The following study is made for GPS L1 C/A signals but is applicable to L5, E1C and E5a.

The first basic objective of this paper is to propose a validation of the multipath pseudorange error simulator through the numerical validation of the electromagnetic prediction of multipath parameters.

Then, the main objective is to propose a multipath pseudorange error model based on the one proposed in [2] adapted to canonical taxi operation scenarios. An example of establishment of this multipath pseudorange error model is proposed for a typical scenario of taxi on a stand taxilane.

\section{Pseudo-range error multipath simulator for aircraft ground surface navigation}

In this first section, the principle and the validation of the GNSS multipath pseudorange error simulator is described.

\subsection{Pseudo-range error multipath simulator principle}

For a given aircraft trajectory and satellite position, the computation of the multipath error is based on a deterministic electromagnetic method applied to an airport scene (Fig. 1). The elements in the scene, e.g. airport buildings or surrounding aircraft, are described by means of a polygonal mesh. The simulator emulates first and second-order interactions as follows.

For first-order interactions, each facet yields a scattered field modeled by means of Physical Optics (PO). Currents on the facet induce an electromagnetic (EM) field by means of Stratton-Chu integrals. This way, each illuminated facet is seen as the origin of one multipath. The characteristics of the multipath are computed taking into account the antenna model which is detailed in [5] and [6].

For second-order interactions, Geometrical Optics $(\mathrm{GO})$ is used to determine the illuminated facets and the associated incident fields of the first interaction. GO is a ray launching method which accounts for the reflection of rays by surfaces e.g. facets here. When an incident ray impacts a surface, it yields reflected rays, whose direction derives from Snell-Descartes laws, and whose amplitude and divergence factor are modified. The divergence factor characterizes the evolution of the field amplitude due to the ray tube divergence with propagation. GO is limited as for instance it predicts a discontinuity of the field at shadow boundaries. The second scattering is obtained with PO similarly to first-order interactions. The reflection over the ground is accounted via the image theorem in both cases.

After passing through the receiver antenna, each scattered field yields one multipath characterized by an amplitude, a phase, a delay and a Doppler shift. Amplitude and phase are directly related to the scattered field while the delay and Doppler shift are assessed geometrically from the satellite position and the aircraft trajectory. Finally, the pseudo-range is determined from multipath parameters via a GNSS receiver model. The receiver model simulates correlator outputs in the presence of multipath.

Since the accuracy of the 3D environment model and aircraft trajectory are limited, the deterministic EM multipath model is enhanced by statistical draws associated with several environment uncertainties. This Monte-Carlo analysis considers randomness for the building positions and orientations in the horizontal plane, their height and materials, as well as the material thicknesses, the ground material and the receiver altitude. At each point of a trajectory, this affects the mean and the variance of the pseudo-range error. 


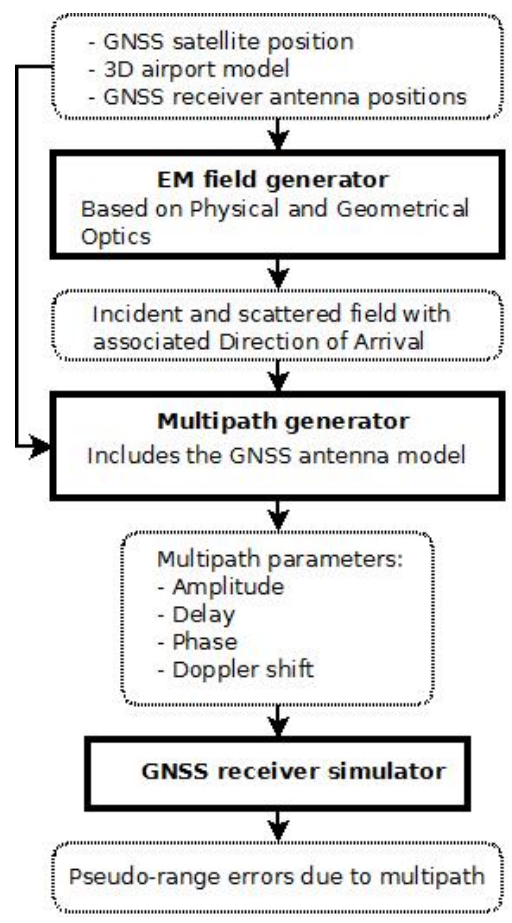

Figure 1: Multipath simulator principle

\subsection{Numerical validation of the EM multipath prediction of the multipath simulator}

In this subsection, a numerical validation of the multipath pseudo-range error simulator is proposed. This presented validation addresses the validation of the EM multipath model. The receiver simulator has been validated in various efforts not related in this paper.

The EM multipath model provides multipath parameters as inputs to the receiver simulator. To validate this multipath parameter prediction, one way is to compare the channel transfer function obtained with the multipath simulator to a reference transfer function derived from a different tool than FMRE. In this paragraph, the reference channel transfer function is obtained using FEKO, an EM software. Under FEKO, the Method of Moments is used. This exact method derives an analytical resolution of Maxwell's equations. The FEKO channel transfer function is computed through Eq. 1.

$$
H_{F E K O}(f)=\frac{E_{R H C P}(\theta, \phi, f)}{E_{R H C P}\left(\theta=0, \phi=0, f=f_{0}\right)}
$$

with

- $\theta$ and $\phi$, the spherical coordinates,

- $f$, the frequency with $f_{0}$ the antenna central frequency equal to $f_{L 1}=1575.42 \mathrm{MHz}$

- $E_{R H C P}$, the righ handed cicrularly polarized electric field,

- and $H_{F E K O}$, the normalized channel transfer function at the frequency $f$ in the direction of arrival $(\theta, \phi)$.

This reference solution is compared to the FMRE predicted transfer function of Eq. 2.

$$
H_{F M R E}(f)=\sum_{n=0}^{N} a_{n} e^{j\left(2 \pi \tau_{n}\left(f+f_{n}^{D o p p}\right)+\phi_{n}\right)}
$$

where

- $a_{n}$, the amplitude of the $n^{\text {th }}$ multipath,

- $\tau_{n}$, the delay of the $n^{t h}$ multipath, 
- $\phi_{n}$, the phase of the $n^{\text {th }}$ multipath,

- $f_{n}^{\text {Dopp }}$, the Doppler frequency of the $n^{\text {th }}$ multipath,

- and $H_{F M R E}$, the FMRE channel transfer function at the frequency $f$ in the direction of arrival $(\theta, \phi)$.

N.B.: To simplify the notation, the transfer functions are written $H(f)$ even if they depend on the direction of arrival and the Doppler frequency is omitted since we consider a static configuration.

The comparison of the transfer functions is executed in the context of a patch antenna mounted on an infinite ground plane and facing a metallic wall of $5 \mathrm{~m}$ by $5 \mathrm{~m}, 60 \mathrm{~m}$ away as presented is Fig. 2 .

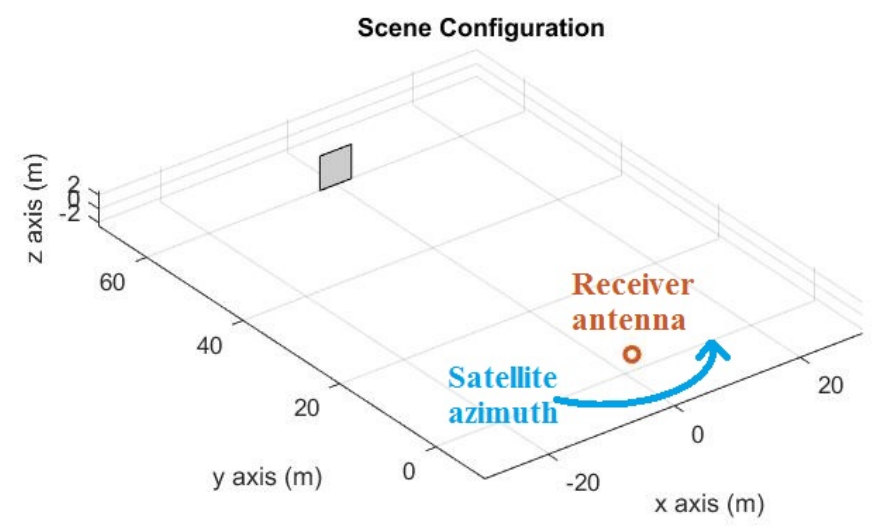

Figure 2: Scene configuration for transfer function comparison

To compare the transfer functions, similarly to [1], the mean square (RMS) difference $\epsilon_{R M S}$ is computed after applying the baseband power spectrum density of the GPS L1 C/A signal (cf. Eq. 3).

$$
\epsilon_{R M S}=\frac{\int_{-B / 2}^{B / 2}\left|S_{G P S_{L 1 C A}} \cdot\left(H_{F M R E}(f)-H_{F E K O}(f)\right)\right|^{2} d f}{\int_{-B / 2}^{B / 2}\left|S_{G P S_{L 1 C A}}\right|^{2} d f}
$$

with the normalized baseband power spectrum density of the GPS L1 C/A signal: $S_{G P S_{L 1 C A}}=\operatorname{sinc}^{2}\left(T_{c}\left(f-f_{L 1}\right)\right)$ where $T_{c}$ the chip spacing is equal to $\frac{1}{f_{c}}=\frac{1}{1.023 e^{6}}=0.9775 \mu \mathrm{s}$.

If the RMS difference is lower than $-20 \mathrm{~dB}$ then it corresponds to a power difference of $1 \%$ and therefore the two predictions fit.

The antenna model under FMRE does not render the frequency dependent-behavior of the antenna on the complete L1 C/A bandwidth (refer to [5]). In fact, the real antenna gain, phase and group delay are varying with the frequency but under the multipath simulator we only consider their value at the antenna central frequency i.e. $f_{L 1}$ for complexity reasons. Therefore, this antenna difference is removed from the FEKO transfer function as follows. Due to the theorem of reciprocity and superposition, we can write

$$
H_{F E K O}(f)=1+\left|H_{F E K O}^{\text {Wall }+ \text { Ant Bias }}(f)\right|-\left|H_{F E K O}^{\text {Ant Bias }}(f)\right|
$$

$H_{F E K O}^{W a l l+A n t ~ B i a s}(f)$ is the transfer function obtained with FEKO for the patch antenna mounted on an infinite ground plane and a $5 \mathrm{~m}$ by $5 \mathrm{~m}$ metallic wall at $60 \mathrm{~m}$. $H_{F E K O}^{\text {Ant Bias }}(f)$ is the transfer function of the same antenna radiating in free space. In the following, $H_{F E K O}(f)$ refers to the transfer function resulting from Eq. 4 and is free of frequency-dependent antenna biases. These transfer functions are plotted on Fig. 3. 


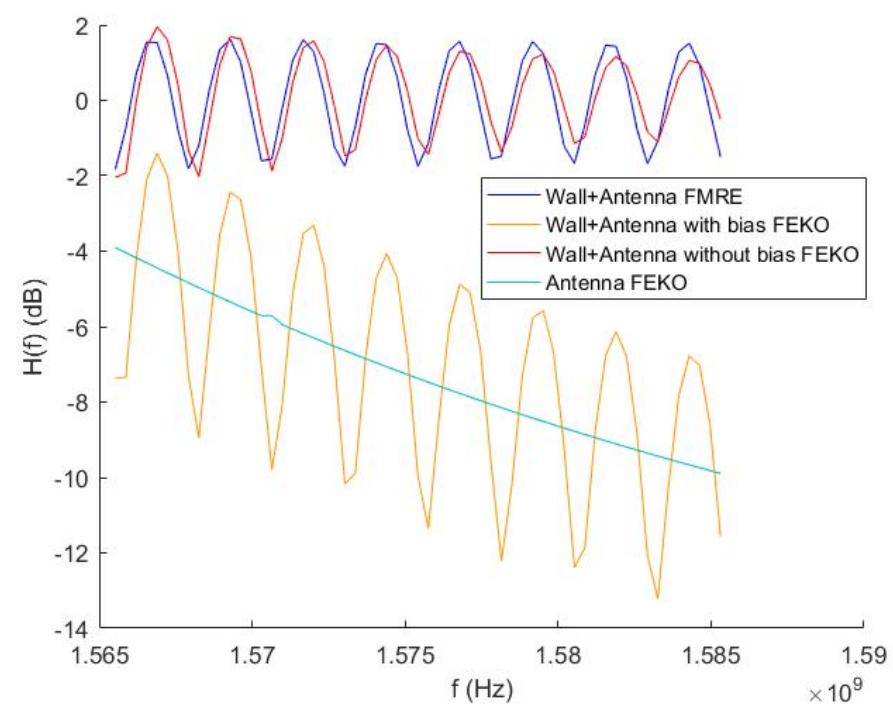

Figure 3: Magnitude transfer function comparison at elevation $5^{\circ}$

As it can be seen on Fig. 3, the major part of the antenna bias has been successfully removed. A decrease of the amplitude of the transfer function is still visible along with the frequency. The FMRE and FEKO transfer functions present the same oscillations for a similar magnitude and fit quite well. These oscillations are characteristics to the presence of a dominant multipath.

The transfer functions for an azimuth from 0 to $360^{\circ}$ and an elevation from 0 to $90^{\circ}$ are shown in Fig. 4 and 5 .

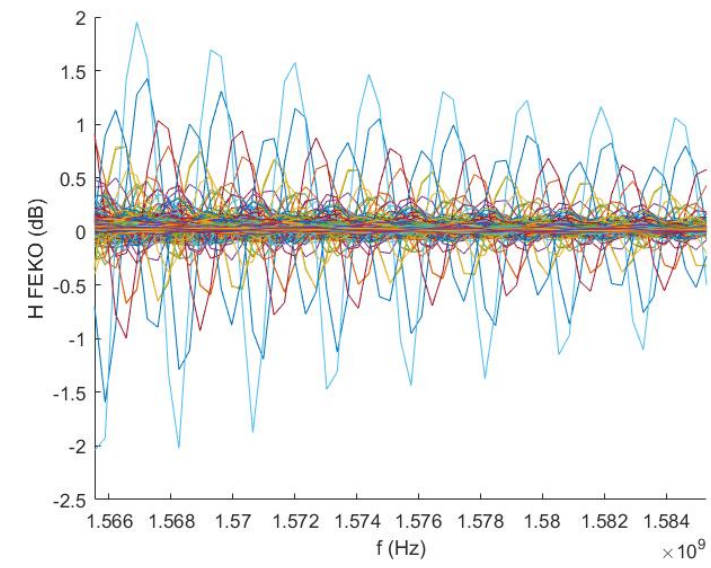

Figure 4: Magnitude of the FEKO transfer function with antenna bias removed for 0 to $360^{\circ}$ of azimuth and 0 to $90^{\circ}$ of elevation

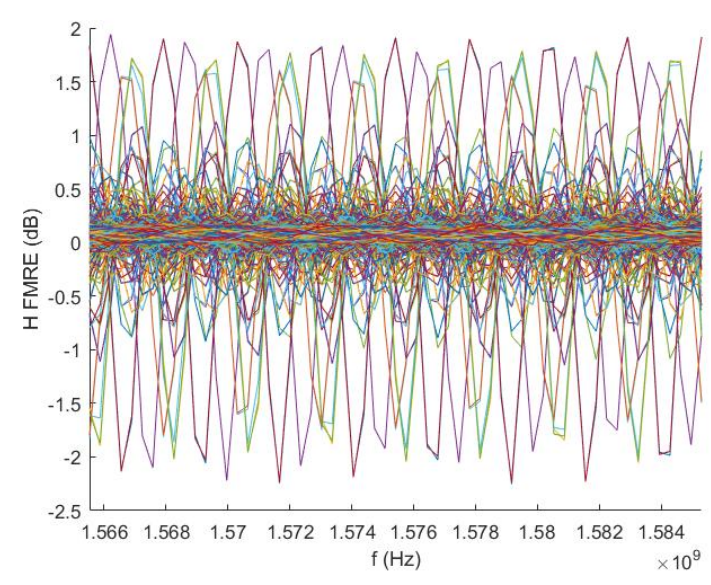

Figure 5: Magnitude of the FMRE transfer function for 0 to $360^{\circ}$ of azimuth and 0 to $90^{\circ}$ of elevation

The period of the oscillations is comparable for FEKO and FMRE transfer functions. The magnitude is of the same order even if we observe a frequency-dependent amplitude residue up to $1 \mathrm{~dB}$ for some directions of arrival. The difference between the two transfer functions according to Eq. 3 is presented Fig. 6. 


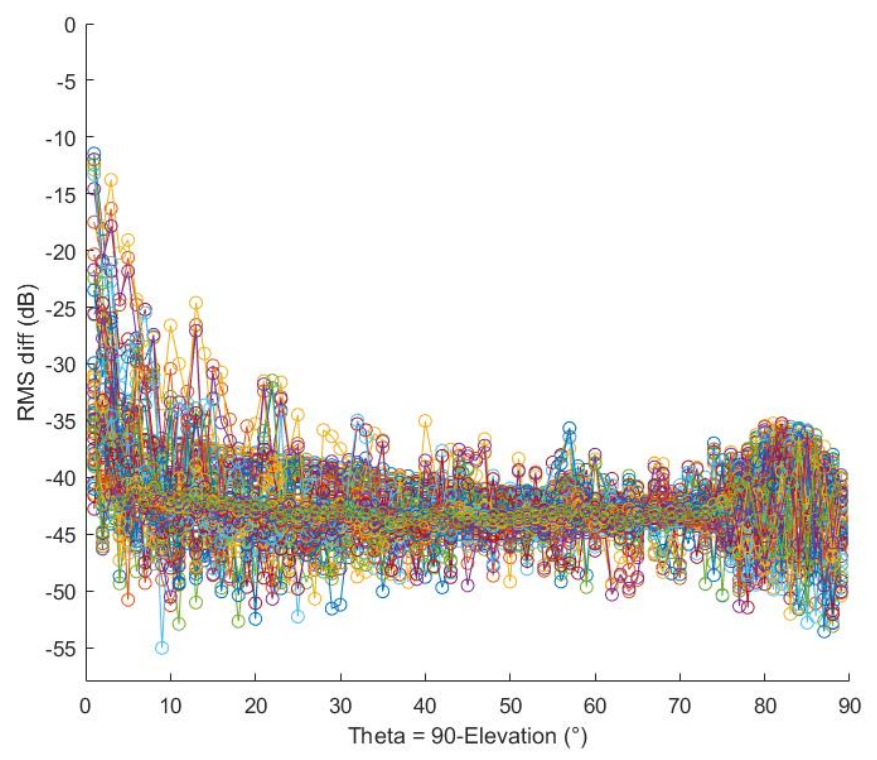

Figure 6: RMS difference of the two transfer functions for 0 to $360^{\circ}$ of azimuth and 0 to $90^{\circ}$ of elevation

On Fig. 6, we can see that the criteria $\epsilon_{R M S}<-20 \mathrm{~dB}$ is mainly respected except for some azimuth at high elevation. In fact, for a satellite close to the zenith, the multipath simulator is still able to predict some multipath while in reality (see Fig. 7), as predicted by FEKO, the major part of the scattered electric field is not redirected towards the antenna.

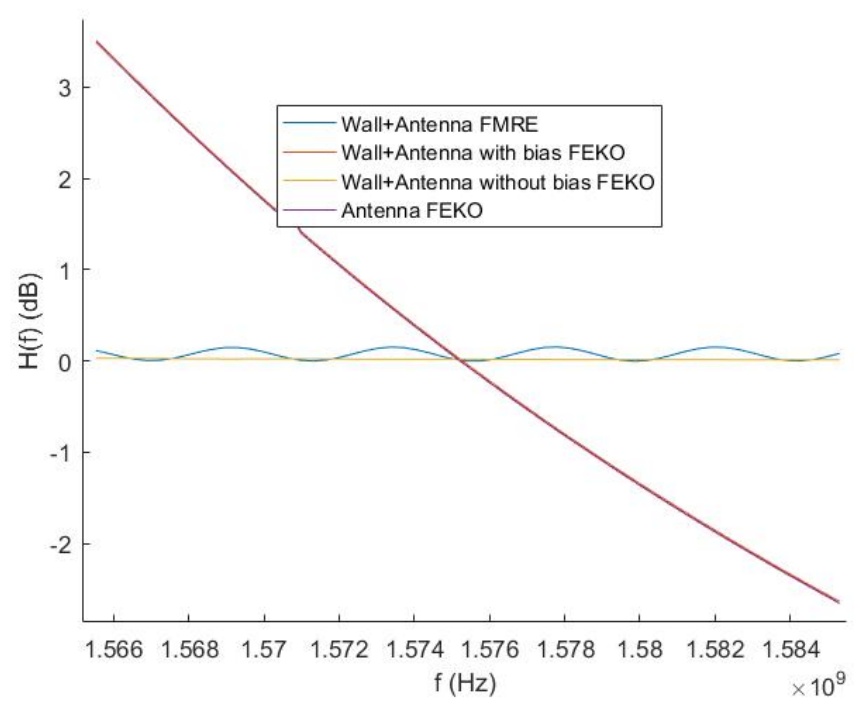

Figure 7: Magnitude transfer function comparison at elevation $89^{\circ}$

These directions with a RMS difference larger than to $-20 \mathrm{~dB}$ only represent 13 cases on 5429 meaning that the RMS criteria is respected for $99,76 \%$ of the directions of arrival and then that the EM prediction of multipath is correct.

The next section illustrates the use of the validated multipath pseudo-range error simulator for measurements comparison.

\subsection{Comparison to measurements performed at ENAC}

A measurement campaign has been performed at ENAC on a rooftop to limit the influence of non predictable obstacles such as pedestrians, bikes or cars and facing a metallic wall to maximize the chance to get a dominant multipath. The antenna used is 
an Antcom G8 Arinc mounted a ground plane. This antenna is a dual-band GPS L1 C/A and L2 patch. We used a Septentrio PolarRX3eTR receiver. The position of the receiver antenna is measured using a Velodyne Lidar. The Lidar image of the scene is shown Fig. 8 and its representation under the multipath simulator is visible Fig. 9.

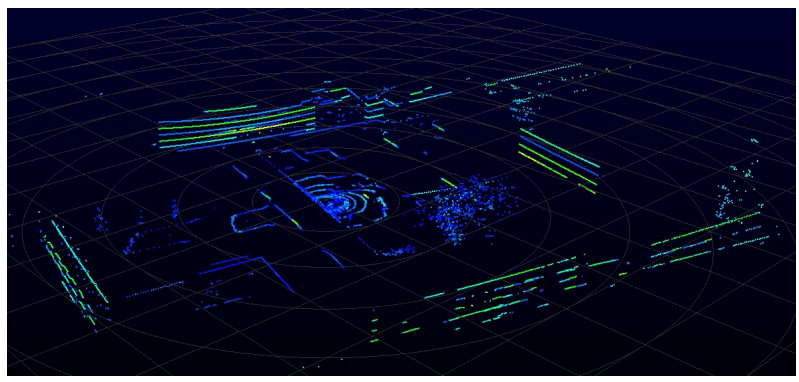

Figure 8: Lidar image of the measurement conditions

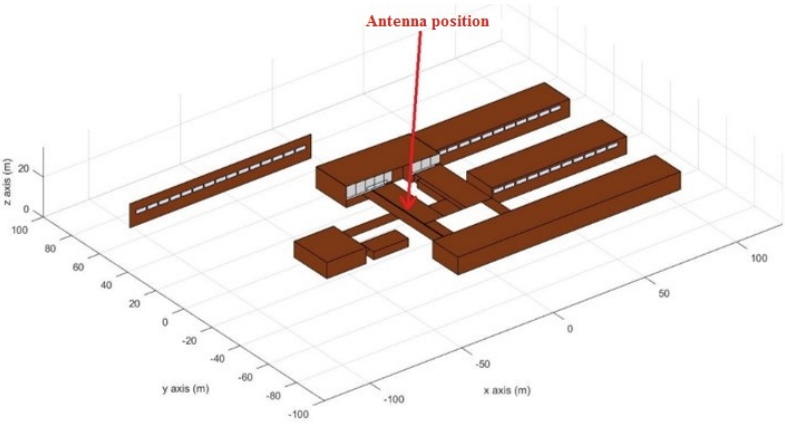

Figure 9: Representation of the measurement environment under the multipath simulator

We measured the code and the phase on L1 C/A and L2 during more than 6 hours. The multipath pseudo-range error is extracted by means of a Code Minus Carrier process presented in details in [7]. The resulting CMC are plotted Fig. 10.

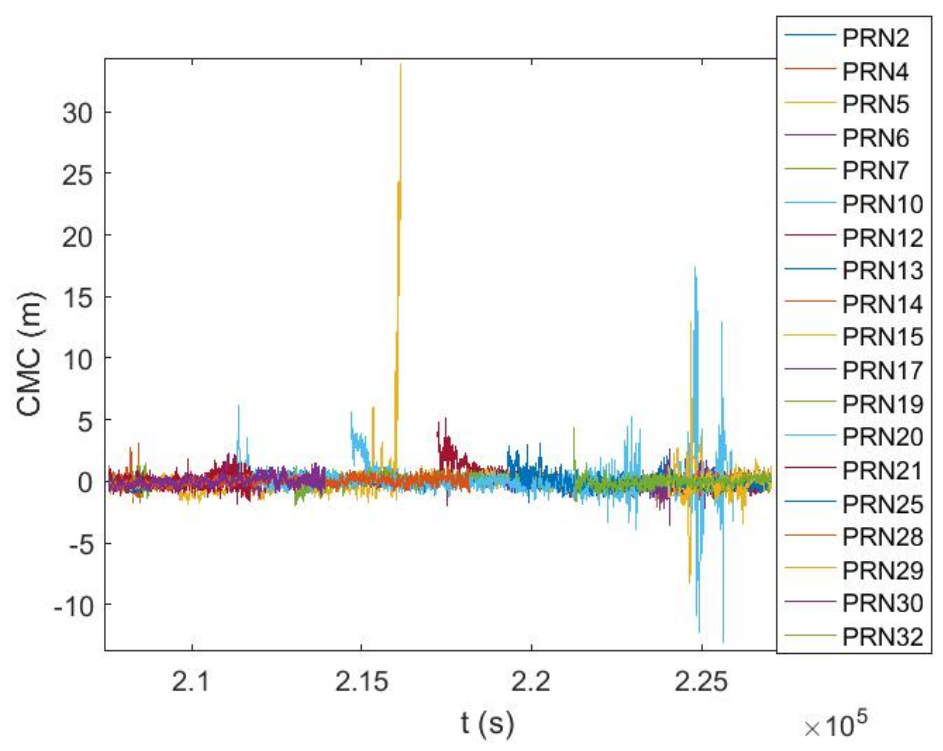

Figure 10: Estimated multipath and noise pseudo-range errors

Peaks on the CMC observable are expected to be due to multipath since they appear only right before the satellite goes out of visibility or right after it came in sight. To determine which satellite is really affected by multipath, the Power Spectral Density of the CMC measurements are shown Fig. 11 and 12. 


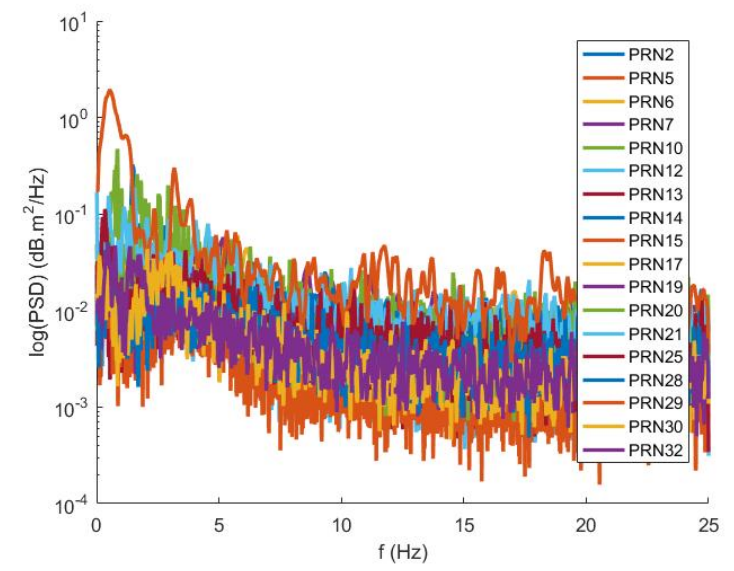

Figure 11: Power Spectral Density function of the CMC observables

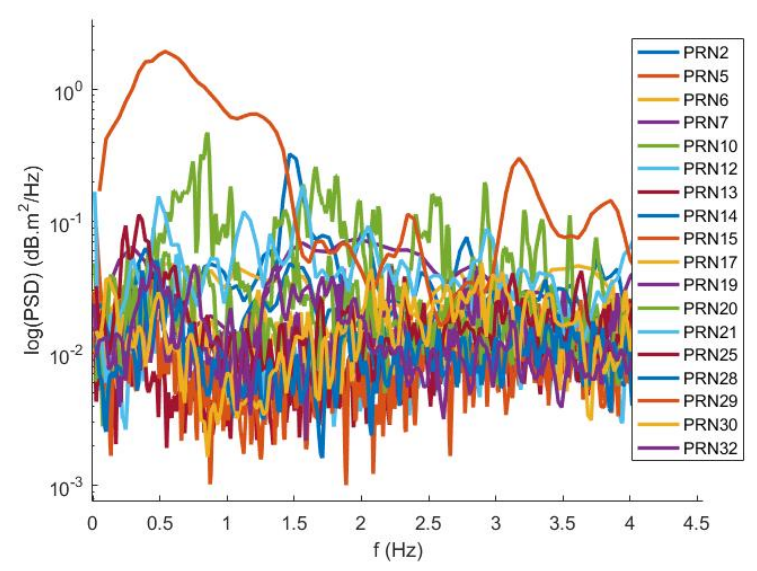

Figure 12: Zoom in low frequencies of CMC's PSD

The existence of multipath is directly linked to the geometry of the scene. Therefore, for a sufficiently long period of observation, the satellite movement is significant enough to see a variation of the multipath parameters. This phenomenon implies that multipath variations are a low frequency component. Higher frequencies of the PSD mainly represent noise and diffuse multipath.

5 satellites seem to have significant low frequency PSD peaks. In the following, it has been chosen to present results for PRN 29 which shows the highest PSD amplitude at low frequency. The azimuth, elevation and CMC of PRN 29 can be seen Fig. 13 and the signal-to-noise ratio Fig. 14.
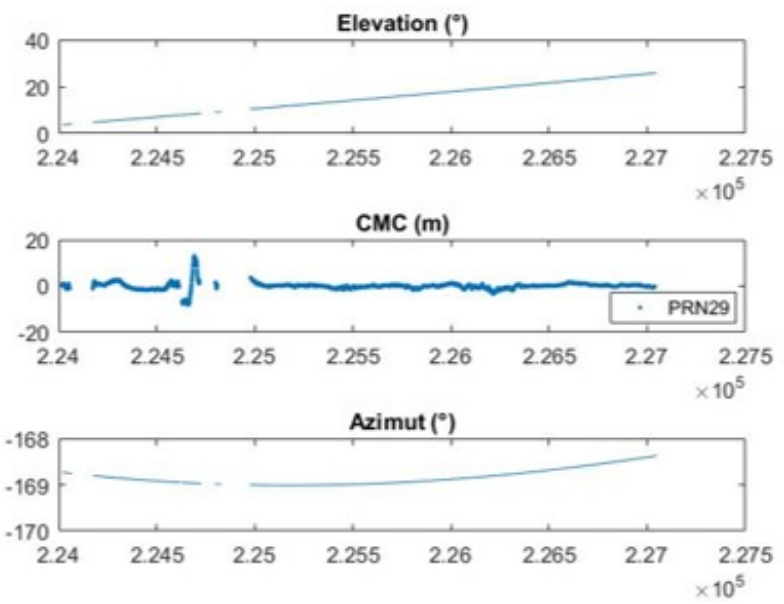

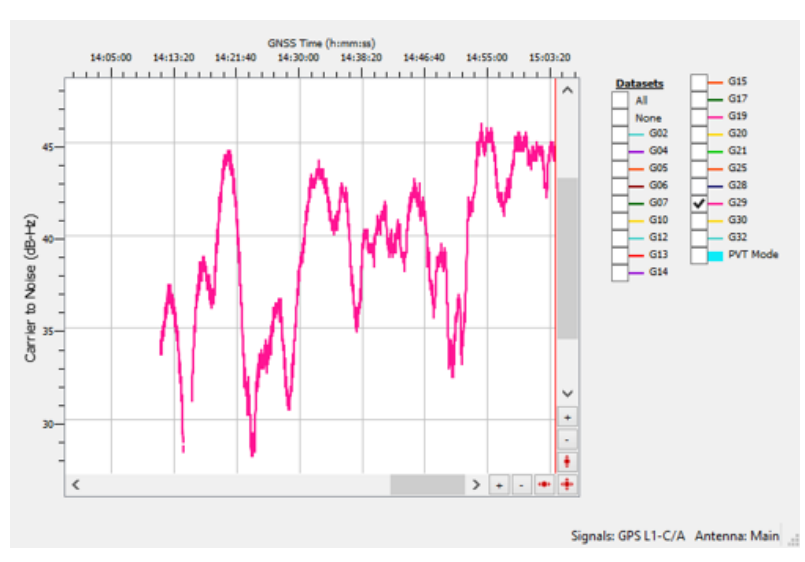

Figure 14: C/N0 over time for PRN 29

Figure 13: Azimuth, elevation and CMC over time for PRN 29

As expected, this satellite is in a configuration where multipath are expected because the elevation starts low and high signalto-noise ratio oscillations appear. We have to note several losses of tracking during the period of visibility. The scene illumination is represented Fig. 15. The measurements campaign was set to get multipath reflections of the metallic wall noted Fig. 15 . According to the illumination plot, this wall is effectively radiating towards the antenna. 


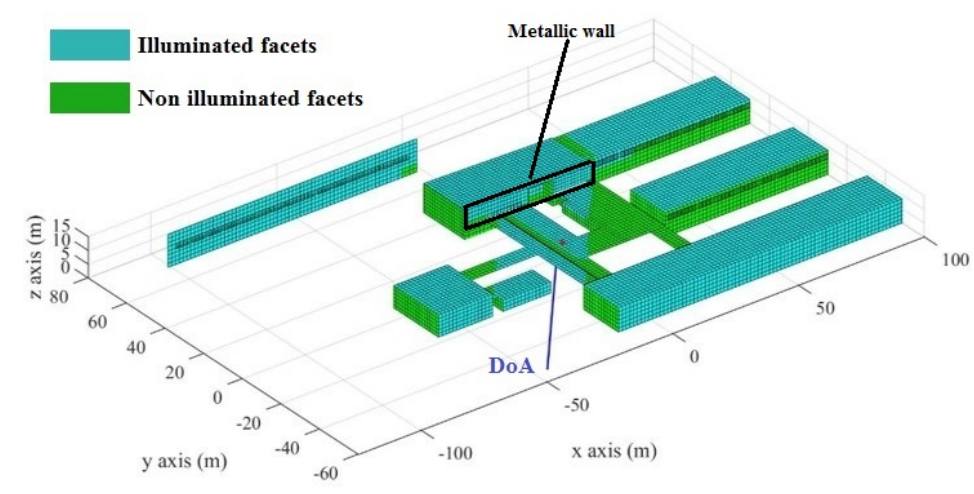

Figure 15: Illumination of the scene by PRN29

The antenna model used under the multipath simulator renders the gain, phase and group delay variations with respect to the direction of arrival of the line-of-sight signal and each multipath incoming at the antenna input. The uncertainties on the scene are reflected by 20 Monte-Carlo draws with the parameters of Tab. 1.

\begin{tabular}{|c|c|c|}
\hline Category & Parameter & Variation \\
\hline Receiver & Receiver altitude & $10 \mathrm{~cm}$ \\
\hline \multirow{3}{*}{ Building geometry } & Horizontal center translation & $1 \mathrm{~m}$ \\
& Vertical height homothetie & $1 \%$ \\
& Horizontal rotation & $3 \%$ \\
\hline \multirow{2}{*}{ Material } & Wall thickness & $50 \mathrm{~cm}$ \\
& Window thickness & $3 \mathrm{~cm}$ \\
& Air layer thickness & $1 \mathrm{~cm} \%$ \\
\hline
\end{tabular}

Table 1: Number of trajectory per aircraft type

The mean and the standard deviation of the predicted multipath pseudo-range error at each epoch is computed and plotted Fig. 16. We have to keep in mind that the CMC values are not noise free contrary to our multipath simulator predictions. To remove this noise term, one could model the signal-to-noise ratio as a function of the elevation and link this to a noise versus elevation model. This would allow us to compare multipath pseudo-range error variances free of noise. But since the 6 hours of measurement campaign are not sufficient to establish this model on this day.

Even if the CMC still includes the noise, the comparison provides good results as seen Fig. 16 and 17 . Two phases can be distinguished: a transient state where the satellite is not locked yet and a permanent state after the last tracking loss. The transient state occurs at low elevation. The loss of tracking can be due to the presence of a tree not modeled in the simulator scene. Trees are not modeled since this multipath simulator is designed for airport navigation only. The prediction oscillations confirm the presence of a dominant multipath. 


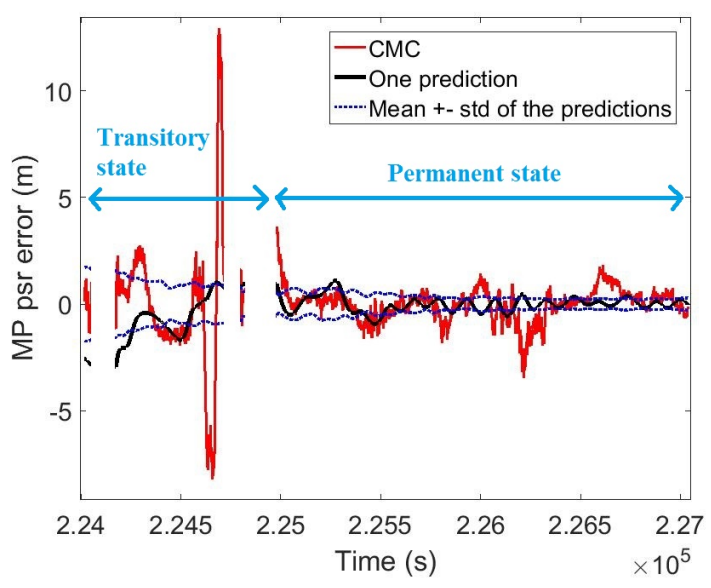

Figure 16: CMC versus mean \pm the standard deviation of the predictions for PRN 29

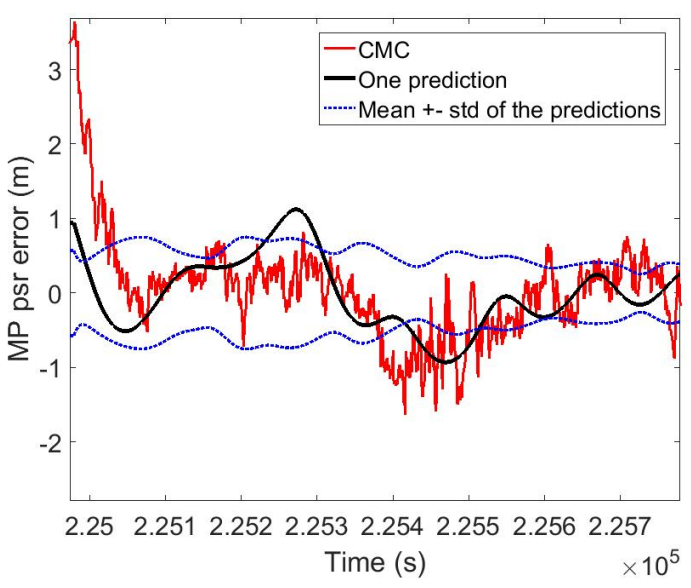

Figure 17: Zoom in the early permanent state of Fig. 16

With Tab. 2, we can compare the mean and the standard deviation of the observed CMC and the predictions of the multipath error variations for both transitory and permanent state. A good agreement of the means and the standard deviations can be observed except for the standard deviation of the transitory state. In fact the peaks occurring right before the loss of tracking is not present in the simulations. This is typically a result of a not modeled obstacle such as a tree or a building detail. Nevertheless, for the permanent state, the means perfectly match and the standard deviations are quite similar taking into account that the measured standard deviation contains a noise term.

\begin{tabular}{|c|c|c|c|}
\hline & Quantity & Tansitory state & Permanent state \\
\hline \multirow{2}{*}{ Measured } & Mean & $-0.36 \mathrm{~m}$ & $-0.16 \mathrm{~m}$ \\
& Standard deviation & $3.19 \mathrm{~m}$ & $0.76 \mathrm{~m}$ \\
\hline \multirow{3}{*}{ Simulated } & Mean & $-0.36 \mathrm{~m}$ & $-0.17 \mathrm{~m}$ \\
& Mean standard deviation & $1.07 \mathrm{~m}$ & $0.36 \mathrm{~m}$ \\
& Minimal standard deviation & $0.58 \mathrm{~m}$ & $0.20 \mathrm{~m}$ \\
& Maximal standard deviation & $1.74 \mathrm{~m}$ & $0.75 \mathrm{~m}$ \\
\hline
\end{tabular}

Table 2: Moments comparison

The comparison between simulated multipath pseudo-range errors and CMC values provides an interesting illustration of the use of the multipath simulator. Even if the comparison with CMC is limited due to the noise presence and the small number of Monte-Carlo draws, we get a good overall accordance.

In this section, a numerical validation of the multipath simulator has been proposed. To illustrate the results which can be made with the multipath simulator, a comparison to measurements performed at ENAC has been developed. These two conclusive steps allow us to go further with this multipath simulator and to propose a multipath ranging error model for airport navigation.

\section{Multipath pseudo-range error model for canonical taxi operation scenarios}

The purpose of this paper is to propose a new GNSS multipath pseudo-range error model adapted to taxi operations on a class F airport. In [2], a multipath ranging error model has been proposed but this model was not airport independent. The next subsections refer to the model presented in [2] and goes further to adapt it to any class $\mathrm{F}$ airport by identifying classical situations.

\subsection{Previous multipath pseudo-range error model for taxi operations from [2]}

First of all, the model of [2] starts by identifying an impact zone. This impact zone is defined as a location on the airport surface where multipath has a significant contribution to the pseudo-range error with respect to the other sources of ranging errors (troposphere, ionosphere, satellite clock and ephemeris inaccuracies and the receiver thermal noise) in steady state. Once this location is delimited, the multipath ranging error model distinguishes a static and a dynamic situation. 


\section{Static configuration}

When the aircraft is not moving in the impact zone, the multipath pseudo-range error $\varepsilon_{M P}$ is decomposed as follows:

$$
\varepsilon_{M P}=b_{A+G}(\Theta, \Phi)+b_{o b s}
$$

where

- $\Theta$ and $\Phi$, the satellite elevation and the aircraft azimuth,

- $b_{A+G}$, the aircraft+ground component induced by the ground reflection, which is considered as a deterministic bias,

- $b_{o b s}$, the oscillating component induced by the $1^{\text {st }}$ and $2^{\text {nd }}$ order interactions with obstacles.

The oscillating component depends on the GNSS receiver antenna radiation pattern model, the GNSS receiver settings, the satellite position, the aircraft azimuth, the aircraft model itself, the 3D model of the airport environment, and the type of ground material. The Probability Density Function (PDF) of the oscillating component $b_{o b s}$ is then over-bounded by a centered Gaussian distribution.

\section{Dynamic configuration}

In the context of a dynamic situation, the multipath ranging error is estimated via Eq. 6.

$$
\varepsilon_{M P}(t)=b_{A+C}(\Theta, \Phi)+u_{o b s}(t)
$$

with

- $b_{A+C}(\Theta, \Phi)$, similar to the static one,

- $u_{\text {obs }}(t)$, the oscillating component induced by the $1^{\text {st }}$ and $2^{\text {nd }}$ order interactions with obstacles, a zero-mean time-dependent error.

The oscillating component $u_{o b s}$ has the same dependency as $b_{o b s}$ but it depends on a trajectory location and orientation dependency as well as an aircraft speed over the trajectory dependency. In [2], it has been chosen to provide a stochastic model of the oscillating component in the impact zone. The true trajectory is modeled by its own statistical distribution drawn from MonteCarlo simulations. In fact, in each Monte-Carlo simulation, each point of a trajectory is randomly chosen within an interval around the true position. This drawn position ensures the true trajectory independence. The Power Spectral Density (PSD) of the oscillating component is over-bounded by a zero-mean $1^{\text {st }}$ order Gauss-Markov process $\mathcal{M}\left(\tau_{d y n}, \sigma_{d y n}\right) . \tau_{d y n}$ and $\sigma_{d y n}$ are respectively the correlation time and the standard deviation. The normalized PSD of the $1^{\text {st }}$ order Gauss-Markov process is given in Eq. 7.

$$
S_{G M}(f)=\frac{2 \sigma_{d y n}^{2}}{\tau_{d y n}\left((2 \pi f)^{2}+\frac{1}{\tau_{d y n}^{2}}\right)}
$$

The over-bounding PSD is chosen by fixing $\tau_{d y n}$ graphically from simulation results. Then the minimal value of $\sigma_{d y n}$ is picked so that the PSD of the Gauss-Markov process over-bounds the estimated PSD.

This multipath error model has been only tested on some specific trajectories on Blagnac airport and therefore, other conditions may lead to different results. The choice of a Gauss-Markov process has also been made to accommodate the use of a further integrity algorithm.

The following multipath pseudo-range error model is independent of the considered airport and the aircraft orientation and trajectory since it is based on canonical scenarios that can be found in ICAO documentation.

\subsection{Canonical taxi operation scenario identification}

Even if an airport is difficult to model due to all the uncertainties of the environment, the airport navigation is quite codified. In the following section, canonical scenarios are identified according to the ICAO airport navigation rules.

In [3], an ICAO airport classification is proposed with respect to the dimensions of the biggest aircraft which can use the platform. This classification is reminded Tab. 3. 


\begin{tabular}{|c|c|c|}
\hline Code letter & Wing span & Outer main gear wheel span \\
\hline $\mathrm{A}$ & Up to but not including $15 \mathrm{~m}$ & Up to but not including $4.5 \mathrm{~m}$ \\
\hline $\mathrm{B}$ & $15 \mathrm{~m}$ up to but not including $24 \mathrm{~m}$ & $4.5 \mathrm{~m}$ up to but not including $6 \mathrm{~m}$ \\
\hline $\mathrm{C}$ & $24 \mathrm{~m}$ up to but not including $36 \mathrm{~m}$ & $6 \mathrm{~m}$ up to but not including $9 \mathrm{~m}$ \\
\hline $\mathrm{D}$ & $36 \mathrm{~m}$ up to but not including $52 \mathrm{~m}$ & $9 \mathrm{~m}$ up to but not including $14 \mathrm{~m}$ \\
\hline $\mathrm{E}$ & $52 \mathrm{~m}$ up to but not including $65 \mathrm{~m}$ & $9 \mathrm{~m}$ up to but not including $14 \mathrm{~m}$ \\
\hline $\mathrm{F}$ & $65 \mathrm{~m}$ up to but not including $80 \mathrm{~m}$ & $14 \mathrm{~m}$ up to but not including $16 \mathrm{~m}$ \\
\hline
\end{tabular}

Table 3: ICAO aerodrome reference code [3]

For example, according to these dimensions an A380 can only navigate on a class F airport. In this same document, ICAO provides a list of the minimal distances between taxiway center lines and between taxiway center line and objects. A minimal wingtip to object distance is also given. These distances vary with the taxi operation sub-phases and the aerodrome reference code. In the following the surface operation areas are in accordance with the ICAO definitions (Fig. 18). The sub-phases of taxi operations which are considered are all the phases from taxi on the rapid exit taxiway to taxi on the aircraft stand lead-in lines.

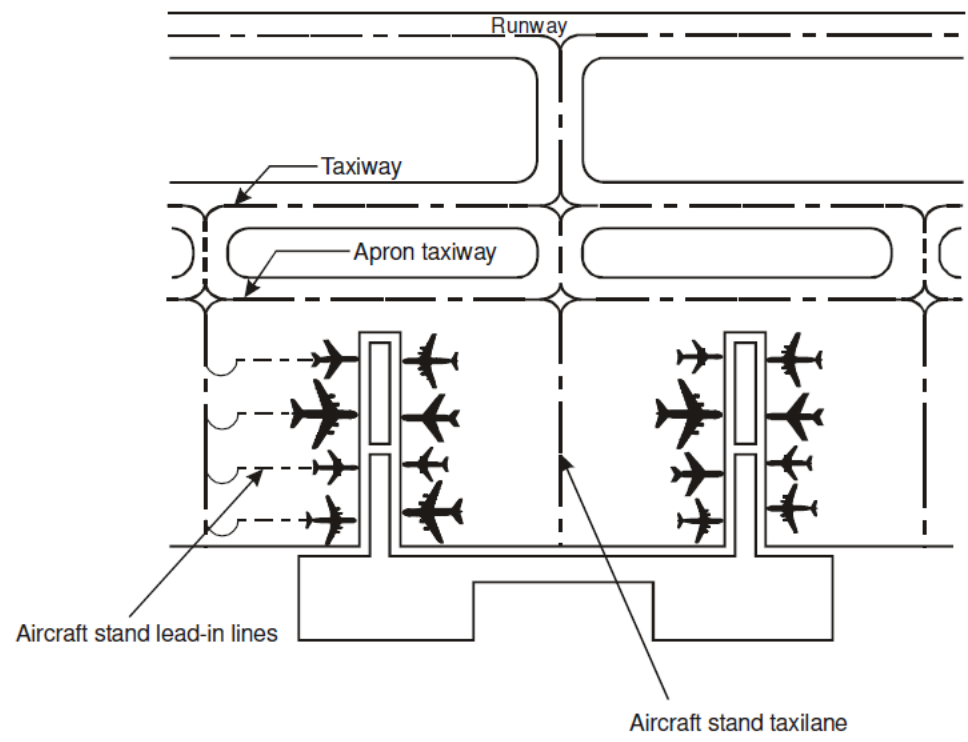

Figure 18: Surface operation areas [3]

The surface clearances for class F airport used in this multipath ranging error model are extracetd from [8] in Tab. 4. 


\begin{tabular}{|l|c|c|l|}
\hline Distance name & Value $(\mathrm{m})$ & Notation & Comments \\
\hline Clearance requirement & 7.5 & $d_{\text {ClearReq }}$ & $\begin{array}{l}\text { Can be increased if required by safety but we focus on } \\
\text { worst case }\end{array}$ \\
\hline Minimum stand spacing & 87.5 & $d_{\text {MiniStdSP }}$ & $\begin{array}{l}\text { Sum of the maximal wingspan authorized and the clear- } \\
\text { ance requirement }\end{array}$ \\
\hline $\begin{array}{l}\text { Stand taxilane center line to } \\
\text { object }\end{array}$ & 50.5 & $d_{T x l 2 o}$ & $\begin{array}{l}\text { The object can be another taxilane center line or an air- } \\
\text { craft parked ... }\end{array}$ \\
\hline $\begin{array}{l}\text { Apron taxiway centerline to } \\
\text { object }\end{array}$ & 57.5 & $d_{A T x w 2 o}$ & $\begin{array}{l}\text { The object can be an aircraft parked, a taxilane center line, } \\
\text { an apron taxiway center line or a taxiway center line ... }\end{array}$ \\
\hline $\begin{array}{l}\text { Taxiway center line to taxi- } \\
\text { way center line }\end{array}$ & 97.5 & $d_{T x w 2 T x w}$ & \\
\hline
\end{tabular}

Table 4: Surface clearance for airport navigation on class F airport [3]

Based on these surface navigation clearances and a study of airport environment, scenarios of ground navigation have been identified. They can be classified by obstacles in the scene:

- scenarios including airport buildings and surrounding parked aircraft in Tab. 5,

- scenarios including only surrounding aircraft in Tab. 6,

- and a scenario including only small obstacles such as cars, trucks, gateway, blast fence ... in Tab. 7.

The purpose of the small obstacles scenario is to determine which obstacles have a multipath pseudo-range error contribution sufficient to be included into other scenarios. To ensure the worst case scenario, the surrounding parked aircraft are always A380 and the navigating aircraft is an A320. Considering an A320 navigating along with A380s may not be the most relevant scenario but it ensures the worst case. The chosen speeds are consistent with usual speeds in zero-visibility conditions.

The different conditions of distances and speed are summarize in the Comments of Tab. 5, 6 and 7. For example, when an aircraft passes by another aircraft, depending if the aircraft at stop is parked on the apron or at stop on another taxiway, the distances between both aircraft are different. All the possible cases are considered in the following tables. It means that for each presented configuration, several scenarios are considered. 


\begin{tabular}{|c|c|c|}
\hline Scenario name & Scenario illustration & Comments \\
\hline $\begin{array}{l}\text { Taxi-in between } \\
\text { two A380 to stand }\end{array}$ & & $\begin{array}{l}\text { If the aircraft is on a taxilane, } D 1= \\
d_{\text {Txl2o }}, D 2=d_{\text {MiniStndSp }}, D 3= \\
d_{\text {ClearReq }} \text { and the speed is from } 5 \mathrm{kt} \text { to } \\
\text { stop. But if the aircraft is on an apron } \\
\text { taxiway, } D 1=d_{A T x w 2 o} \text { and the speed } \\
\text { is from } 5 \mathrm{kt} \text { to stop. }\end{array}$ \\
\hline $\begin{array}{l}\text { Taxi on taxilane or } \\
\text { apron taxiway af- } \\
\text { ter push out be- } \\
\text { tween two A380 } \\
\text { from stand }\end{array}$ & $\begin{array}{l}\text { - Push out, } \\
\text { - Taxion tax } \\
\text { taxiway }\end{array}$ & $\begin{array}{l}\text { If the aircraft is on a taxilane, } D 1= \\
d_{\text {Txl2o }}, D 2=d_{\text {MiniStndSp }}, D 3= \\
d_{\text {ClearReq }} \text { and the speed is from stop to } \\
5 \mathrm{kt} \text {. But if the aircraft is on an apron } \\
\text { taxiway, } D 1=d_{A T x w 2 o} \text { and the speed } \\
\text { is from stop to } 5 \mathrm{kt} \text {. }\end{array}$ \\
\hline $\begin{array}{l}\text { Taxi on taxilane or } \\
\text { apron taxiway par- } \\
\text { allel to stand with } 3 \\
\text { A380 parked }\end{array}$ & & $\begin{array}{l}\text { If the aircraft is on a taxilane, } D 1= \\
d_{\text {Txl2o }}, D 2=d_{\text {MiniStndSp }}, D 3= \\
d_{\text {Clear Req }} \text { and the speed is inferior to } \\
5 \mathrm{kt} \text {. If the aircraft is on an apron taxi- } \\
\text { way, } D 1=d_{A T x w 2 o} \text { and the speed is } \\
\text { between } 5 \text { and } 20 \mathrm{kt} \text {. And if the aircraft } \\
\text { is on a taxiway, } D 1=2 d_{A T x w 2 o} \text { and } \\
\text { the speed is between } 5 \text { and } 20 \mathrm{kt} \text {. }\end{array}$ \\
\hline $\begin{array}{l}\text { Taxi on taxi- } \\
\text { lane/apron taxiway } \\
\text { between two par- } \\
\text { allel stands with } \\
3 \text { A380 parked at } \\
\text { each }\end{array}$ & & $\begin{array}{l}\text { If the aircraft is on a taxilane, } D 1= \\
d_{\text {Txl2o }}, D 2=d_{\text {MiniStndSp }}, D 3= \\
d_{\text {Clear Req }} \text { and the speed is inferior to } \\
5 \mathrm{kt} \text {. If the aircraft is on an apron taxi- } \\
\text { way, } D 1=d_{A T x w 2 o} \text { and the speed is } \\
\text { between } 5 \text { and } 20 \mathrm{kt} \text {. And if the aircraft } \\
\text { is on a taxiway, } D 1=2 d_{A T x w 2 o} \text { and } \\
\text { the speed is between } 5 \text { and } 20 \mathrm{kt} \text {. }\end{array}$ \\
\hline
\end{tabular}

Table 5: Scenarios including buildings 


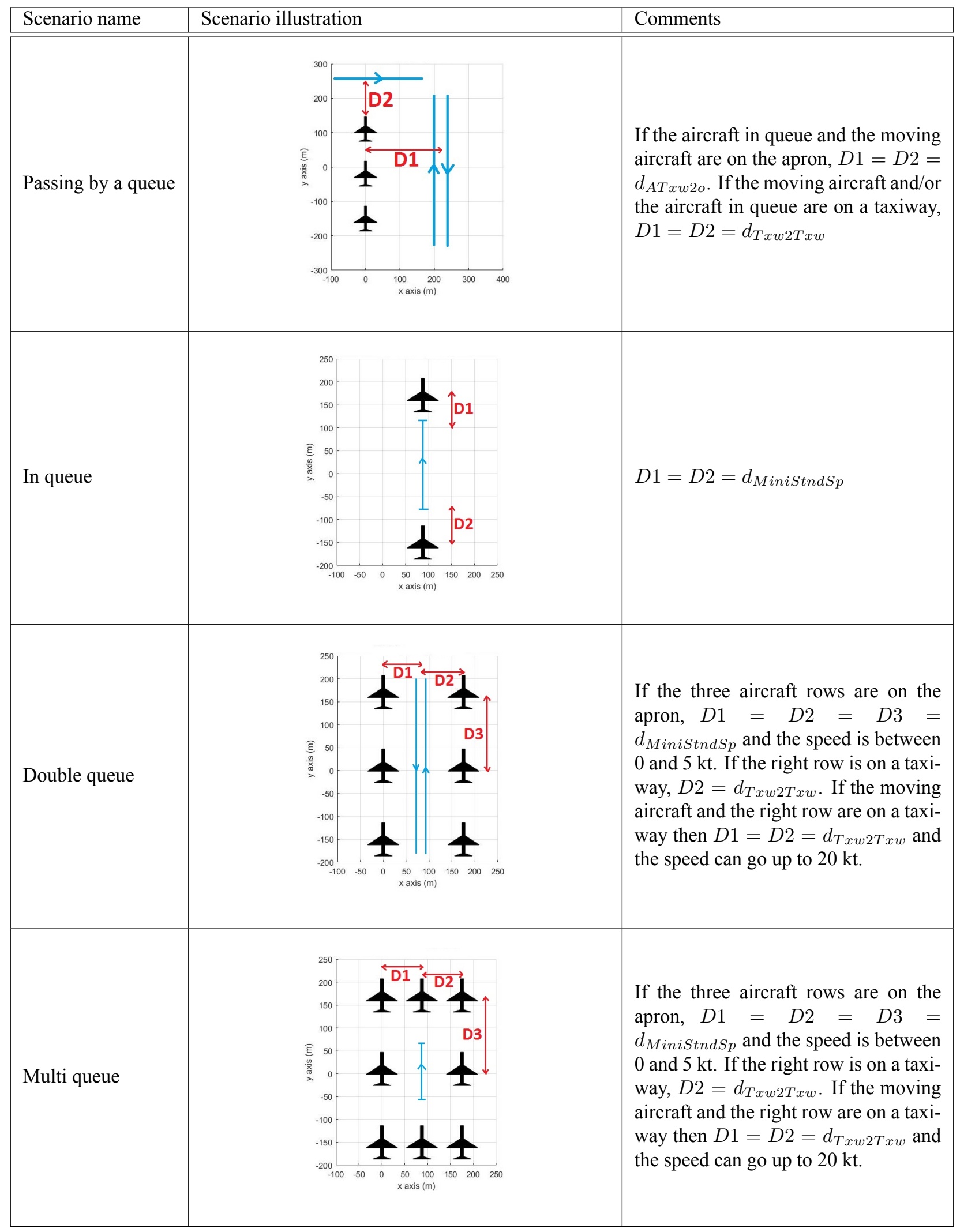

Table 6: Scenarios including only aircraft 


\begin{tabular}{|c|c|c|}
\hline Scenario name & Scenario illustration & Comments \\
\hline $\begin{array}{l}\text { Passing by a small } \\
\text { obstacle }\end{array}$ & & $\begin{array}{l}D 1=d_{A T x w 2 o}, 360^{\circ} \text { trajectory at } 5 \mathrm{kt} \\
\max .\end{array}$ \\
\hline
\end{tabular}

Table 7: Small obstacle scenario

The proposed multipath ranging error model aims at providing the mean and the variance of the multipath pseudo-range error for each canonical scenario. The global error model for a given aircraft trajectory from leaving the gate to entering the runway or from taking the rapid exit taxiway to parking at the gate will be a juxtaposition of these canonical scenarios.

The following section presents the multipath ranging error model applied for each of these scenarios.

\subsection{Establishment of the multipath pseudo-range error model}

For each scenario, hundreds to thousands Monte-Carlo draws are computed with the multipath simulator. The parameters of the Monte-Carlo draws are :

- the receiver antenna altitude rendering the uncertainty on the position of the antenna,

- the building position and orientation to account for the environment geometric uncertainties,

- the building material permittivities and thicknesses,

- the building heights,

- the building facade materials distribution to be independent of the type of building, depicted Fig. 19,

- the satellite azimuth.

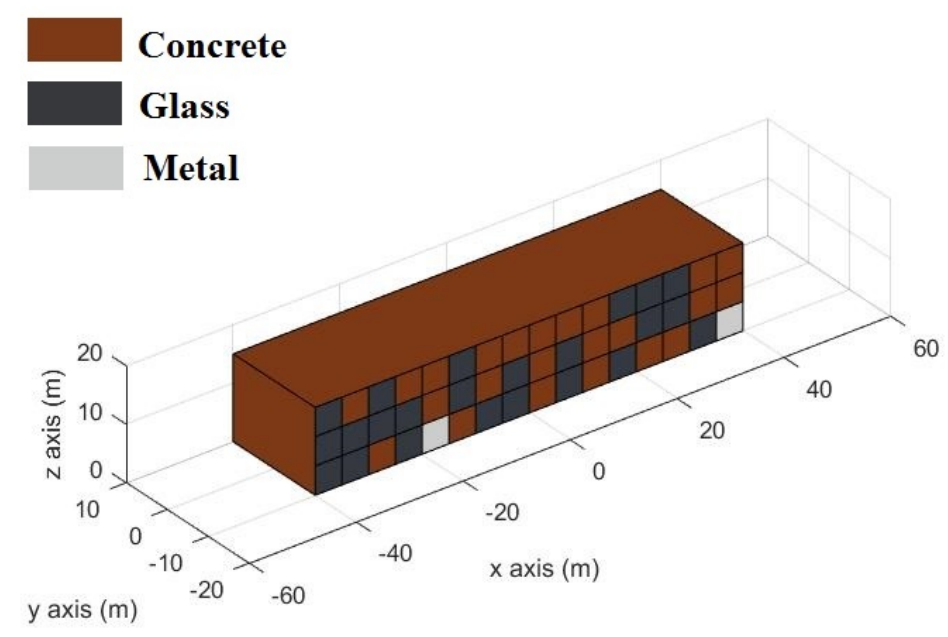

Figure 19: Building random material distribution for a ratio concrete/metal/glass of 50/10/40\% 
Therefore, the obtained GNSS multipath pseudo-range error model reflects the uncertainty on the previously listed parameters. The model is also made to be independent of the airport considered. The different aircraft orientations and trajectories are taken into account as different scenarios. Finally, the list of input parameters is as follows: the satellite elevation, the navigating aircraft type and the sub-phase of taxi operation via the assessed scenario. The navigating aircraft type is taken into account in the antenna+aircraft model where the airframe multipath is assessed and in the scene as the altitude of the receiver antenna depends on the dimensions of the aircraft.

Similarly to the dynamic configuration of the multipath ranging error in [2], we propose to over-bound the Power Spectral Density (PSD) of the multipath pseudo-range error using a first order Gauss-Markov process.

Contrary to what was made in [2], the airframe multipath is gathered with the other obstacle multipath before being aggregated into delay bins. The deterministic bias $b_{A+C}$ cannot be retrieved in the final simulated multipath pseudo-range errors. Therefore, it has been chosen to over-bound the complete multipath pseudo-range error $\epsilon_{M P}$ by a Gauss-Markov process.

$$
\epsilon_{M P}(t)=U_{o b s}(t)
$$

with $U_{o b s}$ a first order Gauss-Markov process rendering the influence of the aircraft structure, the ground and the obstacles.

The parameters of this Gauss-Markov process are determined as follows. First, to ensure the independence of the ranging error over-bound to the satellite azimuth, for one elevation, we aggregate the PSDs over all the azimuths. Then, for a range of correlation time, the Gauss-Markov density larger in each point than the maximum of the simulated PSDs is computed. Among these PSDs, the Gauss-Markov density with the minimal standard deviation is kept for each considered correlation time. The search is performed through a simple dichotomy. Then the optimal over-bounding Gauss-Markov density is chosen as the one minimizing the integral difference

$$
\int_{f} S_{\sigma_{m i n}}(\tau, f) d f-\int_{f} S_{\text {simu }}^{+}(f) d f
$$

with $S_{\sigma_{m i n}}$ the PSD with a minimal standard deviation for the given correlation time $\tau$ and $S_{\text {simu }}^{+}$the maximum of the simulated PSDs at each frequency. The way to proceed is presented in the next section with the example of taxi on a stand taxilane.

\section{Example of multipath pseudo-range prediction for taxi on stand taxilane}

To illustrate the establishment of this multipath pseudo-range error model, in this section we look at a scenario of taxi on a stand taxi lane between two airport buildings with 6 A380 parked.

Fig. 20 shows a representation of the scene under the multipath simulator. The navigating A320 is moving along a straight trajectory of $80 \mathrm{~m}$ at $3 \mathrm{kt}$. Due to the geometric symmetry of the scene, the satellite describes only half the space i.e. the satellite azimuth takes a range between 0 and $180^{\circ}$. The azimuth is given relatively to the $\mathrm{x}$-axis. The receiver RF filter has a ideal infinite bandwidth and the signal considered is the GPS L1 C/A. A total of 500 Monte-Carlo draws are performed.

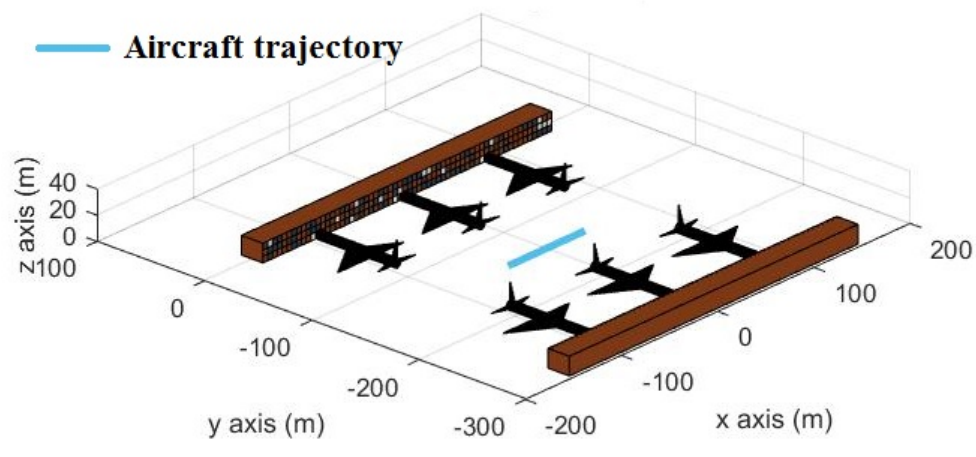

Figure 20: Taxi on aircraft stand taxilane

Fig. 21 presents the multipath pseudo-range errors obtained at elevation $10^{\circ}$ and azimuth $60^{\circ}$ for some Monte-Carlo draws. The associated PSD are plotted in Fig. 22. 


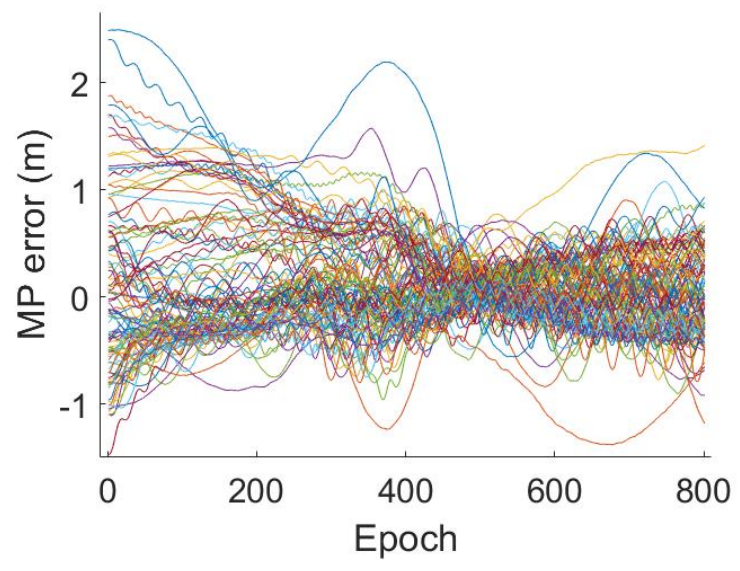

Figure 21: Multipath pseudo-range errors obtained with the different Monte-Carlo draws for an elevation of $10^{\circ}$ and an azimuth of $60^{\circ}$

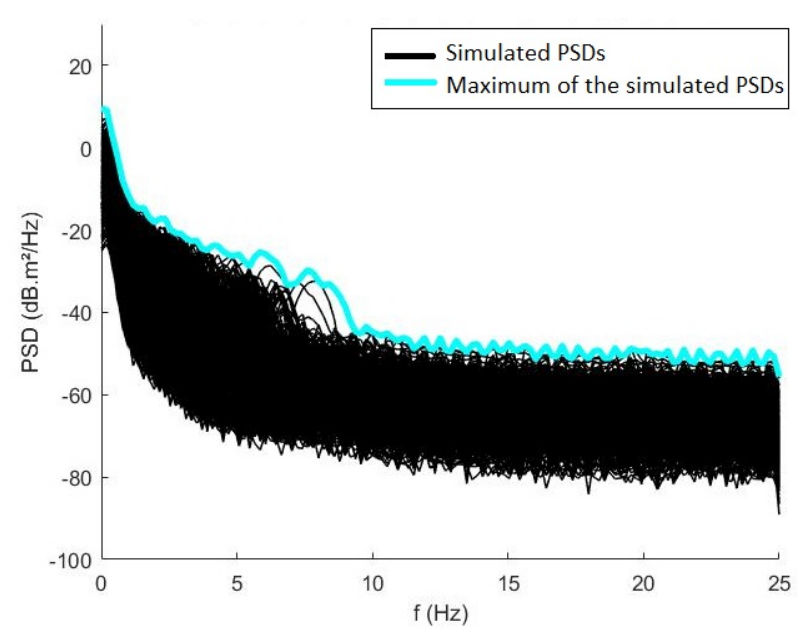

Figure 22: Power spectral density of the multipath pseudo-range errors obtained with the Monte-Carlo draws for an elevation of $10^{\circ}$ and all the considered azimuths

Then, the simulated multipath pseudo-range errors are gathered to compute the global mean PSD for a given elevation. The over-bounding Gauss-Markov process is chosen according to the methodology presented in Section 2.3. Fig. 24 presents the over-bounding Gauss-Markov fitting all simulated PSDs.

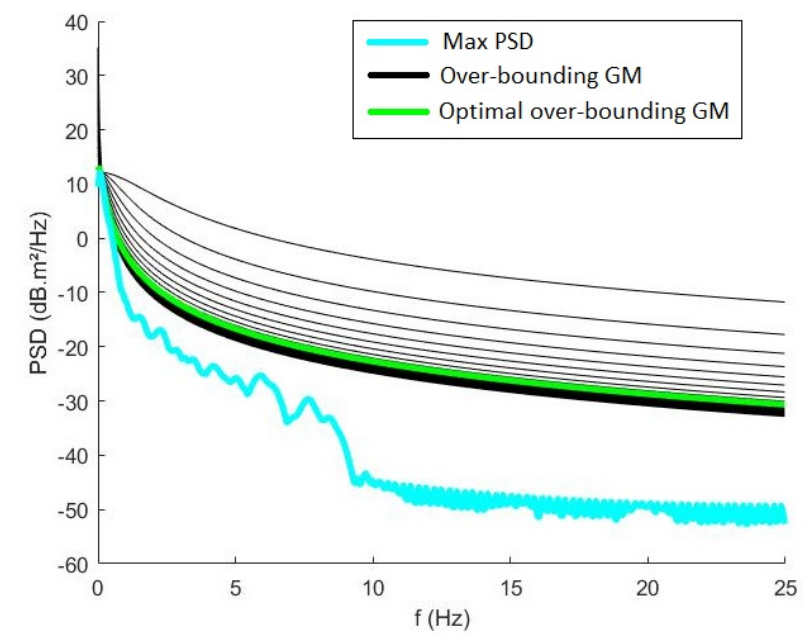

Figure 23: Optimal over-bounding Gauss-Markov determination

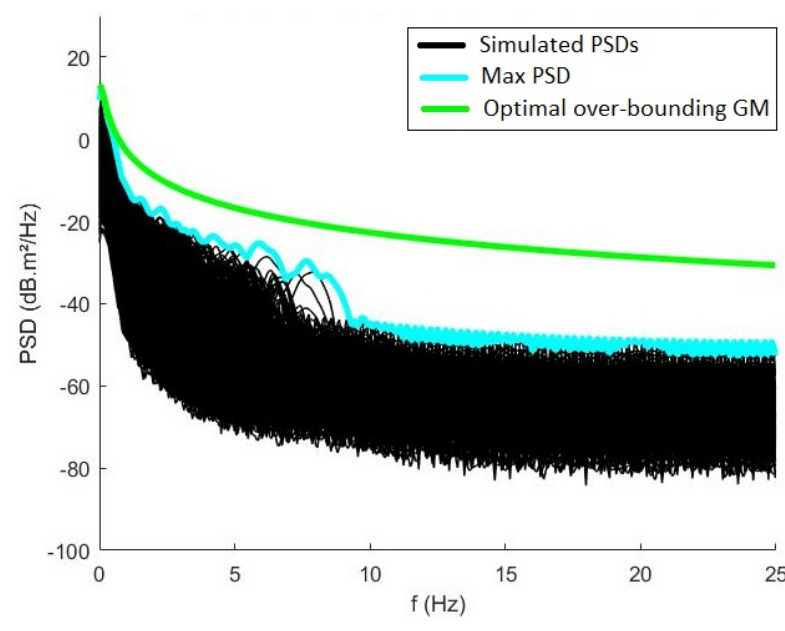

Figure 24: Total simulated PSDs with max and overbounding PSDs

This process is repeated for elevation $5^{\circ}, 15^{\circ}, 30^{\circ}, 45^{\circ}$ and $70^{\circ}$. The detailed parameters of each over-bounding distribution are summarized in Tab. 8. 


\begin{tabular}{|c|c|c|}
\hline Elevation $\left(^{\circ}\right)$ & Correlation time $(\mathrm{s})$ & Standard deviation $(\mathrm{m})$ \\
\hline 5 & 0.8 & 3.6 \\
\hline 10 & 0.8 & 3.2 \\
\hline 15 & 0.8 & 2.5 \\
\hline 30 & 0.4 & 1.7 \\
\hline 45 & 0.3 & 2.1 \\
\hline 70 & 0.3 & 1.6 \\
\hline
\end{tabular}

Table 8: Over-bounding Gauss-Markov parameters

The standard deviations are of the meter level and as expected decrease with the elevation. It can be noted that at elevation $45^{\circ}$ the standard deviation is higher than at $30^{\circ}$. This can be explained by the fact that we considered only 6 different azimuths. Therefore the presented standard deviations don't represent the complete satellite geometry.

Besides, the correlation times are very small and decrease with the elevation. The evolution of the correlation time seems to present an anomaly. Indeed, for a satellite at high elevation, a small satellite position change is expected to have a small impact on the simulated multipath and therefore the multipath pseudo-range errors should be correlated over a longer period. But the presented scenario corresponds to a $16 \mathrm{~s}$ trajectory at $50 \mathrm{~Hz}$ which prevents from getting access to low frequency PSD components. An extension of this study to lower frequency and more azimuths should enable to determine more accurately the correlation time and the standard deviation.

\section{CONCLUSION}

To conlude, the Fortran Multipath Range Error simulator principle has been presented. The outputs of the simulator have been illustrated through comparison to measurements performed at ENAC. Then, a numerical validation of the electromagnetic multipath prediction has been proposed based on transfer functions comparison to the FEKO reference. Then after reminding the work of [2], we adapted a multipath pseudo-range error model for aircraft navigation on reference code F airport. This model is built for canonical scenarios. Its input parameters are the navigating aircraft type, the satellite elevation and the taxi operation sub-phase considered as among a list of canonical scenarios. In this model, the power spectral density of the multipath pseudorange error is over-bounded by a first order Gauss-Markov PSD which seems to fit quite well in the example of taxi on a stand taxilane.

To go further, a study of this scenario with a smaller azimuth grid step will be performed to get access to a better estimation of the correlation time and the standard deviation. Then this multipath ranging error model will be considered as the input of an hybridization algorithm to estimate a navigation solution for class $\mathrm{F}$ airport navigation.

\section{ACKNOWLEDGMENTS}

The authors thank GSA and Airbus for founding this research.

\section{REFERENCES}

[1] A. Chen, A. Chabory, A.C. Escher, and C. Macabiau. Development of a GPS Deterministic Multipath Simulator for an Efficient Computation of the Positioning Errors. Proc. ION GNSS+, September 2009.

[2] L. Montloin, L. Azoulai, A. Chen, A. Martineau, C. Milner, A. Chabory, and C. Macabiau. GNSS multipath error model for airport surface operations. 25th International Technical Meeting of The Satellite Division of the Institute of Navigation, ION GNSS+ 2012, September 2012.

[3] ICAO. Annex 14 to the Convention on International Civil Aviation - Volume I, Aerodrome Design and Operations. Technical report, ICAO, July 2013.

[4] A. Chen, A. Chabory, A.-C. Escher, and C. Macabiau. Hybrid deterministic-statistical GPS multipath simulator for airport navigation. CECom 2010, 20th International Conference on Applied Electromagnetics and Communications, pages 1-4, September 2010 .

[5] C. Amielh, A. Chabory, C. Macabiau, and L. Azoulai. Importance of the Antenna Model to Assess GNSS Multipath in Airport Environments. IEEE USNC-URSI Radio Science Meeting 2018, pages 109-110, July 2018. 
[6] C. Amielh, A. Chabory, C. Macabiau, and L. Azoulai. Including the Aircraft and the Antenna in a Wide Band Aeronautical LMS Channel Model. EuCAP 2020, CS20 Assessment and Modeling of Antennas and Radio Channels Jointly, March 2020.

[7] C. Amielh, A. Chabory, C. Macabiau, and L. Azoulai. Validation of Existing GNSS Multipath Model. ION GNSS+ 2017, pages 41-8, September 2017.

[8] ICAO. Aerodrome Design Manual - Part 2 - Taxiways, Aprons and Holding Bays - 4th edition. ICAO, 2005. 